\title{
Potential of an estuarine salt marsh plant (Phragmites australis (Cav.) Trin. Ex Steud) for phytoremediation of bezafibrate and paroxetine
}

\author{
Sofia Dias · Bárbara Correia $\cdot$ Pedro Fraga-Santiago $\cdot$ Cristiana Silva • \\ Paula C. Baptista $\cdot$ Carlos R. Gomes $\cdot$ C. Marisa R. Almeida $(i)$
}

Received: 8 November 2019/Revised: 22 March 2020/Accepted: 28 March 2020

(C) Springer Nature Switzerland AG 2020

\begin{abstract}
This study aimed to evaluate the potential of a salt marsh plant and its rhizosphere microorganisms for the removal of two pharmaceutical compounds, bezafibrate and paroxetine, from estuarine environment. Plants were exposed for 7 days to a simplified estuarine medium, elutriate solution with or without sediment, doped with bezafibrate or paroxetine. Tests were done in absence and presence of nutrients or copper. Phragmites australis (Cav.) Trin. Ex Steud, alone or with the sediment microbial

Guest editors: Franziska Eller, Hans Brix, Brian K. Sorrell \& Carlos A. Arias / Wetland ecosystems: functions and use in a changing climate
\end{abstract}

Electronic supplementary material The online version of this article (https://doi.org/10.1007/s10750-020-04245-7) contains supplementary material, which is available to authorized users.

S. Dias · B. Correia · C. Silva · C. R. Gomes .

C. M. R. Almeida $(\square)$

CIIMAR - Interdisciplinary Centre of Marine and

Environmental Research, University of Porto,

Terminal de Cruzeiros do Porto de Leixões, Avenida

General Norton de Matos, S/N, 4450-208 Matosinhos,

Portugal

e-mail: calmeida@ciimar.up.pt

S. Dias

Faculty of Engineering, University of Porto, Rua Dr.

Roberto Frias, s/n, 4200-465 Porto, Portugal communities, contributed for pharmaceuticals removal. In the presence of $P$. australis, for paroxetine a $65 \%$ removal was observed. Removal increased up to $90 \%$ when sediment was present. For bezafibrate, removals reached ca. $47 \%$ in $P$. australis presence, increasing to ca. $70 \%$ when nutrients were added to the medium, indicating a good nutritional state can contribute for a higher compound removal. When $\mathrm{Cu}$ was added, $75 \%$ removal for bezafibrate and $95 \%$ removal for paroxetine were observed indicating the metal might influence the removal of the pharmaceuticals. Overall, the plant and its rhizosediments and associated microorganisms showed potential for pharmaceuticals removal from estuaries, eventually degrading the selected compounds, a feature requiring more research. Results indicate that phytoremediation could be a viable option for eliminating/diminishing

\footnotetext{
B. Correia · P. C. Baptista

Escola Superior Agrária, Instituto Politécnico de

Bragança, Alameda de Santa Apolónia,

5300-253 Bragança, Portugal

P. Fraga-Santiago

Facultad de Biología, Campus Vida, Universidad de Santiago de Compostela, Calle Lope Gómez de Marzoa, s/n, 15782 Santiago de Compostela, La Coruña, Spain

C. Silva · C. R. Gomes

Faculty of Sciences, University of Porto, Rua do Campo Alegre 790, 4150-171 Porto, Portugal
} 
the environmental impact of pharmaceutical compounds in estuarine areas.

Keywords Contaminants of emergent concern Estuaries · Pharmaceuticals · Phragmites australis (Cav.) Trin. Ex Steud · Rhizoremediation

\section{Introduction}

An increase in the demand for the Earth's limited supply of freshwater has been originated by the exponential growth of human population. This exponential growth also leads to higher input of contaminants into the environment, including contaminants which are currently getting the attention from environmental regulators, i.e., contaminants of emerging concern (CECs). These contaminants include, among others, human and veterinary pharmaceuticals, personal care products, steroid hormones and surfactants (Taheran et al., 2018). At present time, most of them are not regulated and are continuously released into the environment (showing a, so-called, "pseudopersistence"), which leads to damaging effects at ecological and human level, such as endocrine disruption, carcinogenicity and antibiotic resistance (Bai et al., 2018; Sophia \& Lima, 2018; Taheran et al., 2018). Examples of pharmaceuticals are paroxetine, an antidepressant drug, and bezafibrate, a cholesterol lowering drug, and both have already been found in effluents from WWTPs, namely in Portugal (Pereira et al., 2014; Silva et al., 2014).

Estuaries are highly productive ecosystems that have an important role in biogeochemical cycles. However, they are also very fragile ecosystems that suffer from high anthropogenic pressures receiving all type of contaminants (Fernandes et al., 2017). Most of these contaminants can be dissolved in water, accumulated in estuarine sediments and/or bioaccumulated in organisms (Sun et al., 2012), causing serious effects in several organisms, ecosystem degradation, habitats deterioration and ultimately affecting human beings. Taking in consideration that most WWTPs effluents are discharged into rivers, it is expected that CECs are found in estuarine areas. In fact, several pharmaceutical compounds have been found in Portuguese rivers and estuaries (Madureira et al., 2010; Paíga et al., 2016; Barbosa et al., 2018; Reis-Santos et al., 2018;
Sousa et al., 2019) as well as in other parts of the world (Thomas \& Hilton, 2004; López-Serna \& Petrović, 2012; Yan et al., 2015; Aminot et al., 2016; Cantwell et al., 2018), mainly due to inefficient removal at wastewater treatment plants (WWTPs). Pharmaceutical detected included for instance, carbamazepine, diazepam, fenofibric acid, propranolol, trimethoprim and sulfamethoxazole (Madureira et al., 2010) and fluoxetine, ibuprofen, salicylic acid and ketoprofen (Paíga et al., 2016). Bezafibrate was also among the pharmaceuticals detected in Portuguese rivers and estuaries (e.g., Barbosa et al., 2018, Reis-Santos et al., 2018).

Hence, new remediation and recovery strategies are needed for the removal of these new and emerging pollutants from estuaries as they are very important ecological areas (Fernandes et al., 2017).

A possible methodology to recover and remediate contaminated environments is phytoremediation. This technology, based on the natural processes, uses plants and associated microorganisms to remove, accumulate, metabolize, absorb and/or degrade organic and inorganic pollutants from contaminated media (soil, water and air) (Fernandes et al., 2017). The possibility of using salt marsh plants to control pollution by phytoremediation has been studied, for instance, to treat estuaries contaminated with metals (e.g., da Silva et al., 2014).

More recently, the potential of Phragmites australis (Cav.) Trin. Ex Steud. to attenuate the concentration of CECs in water or sediment contaminated with pharmaceuticals has been evaluated in a few studies (Carvalho et al., 2012, 2013; Fernandes et al., 2015; Sauvêtre \& Schröder, 2015). However, studies on CECs phytoremediation in estuarine environments are scarce and, considering that each compound and its interaction with others compounds can have different effects on plants processes, more research is need on this topic. Fernandes et al. (2015) showed the potential of $P$. australis, to phytoremediate a veterinary antibiotic, enrofloxacin, showing also that in the case of phytoremediation of organic pollutants, microorganisms have a significant role. In fact, microorganisms can biodegrade organic pollutants by themselves. But microorganisms can also be supported by plants in biodegradation processes. Plants are known to stimulate microbial communities changing their structure (Ribeiro et al., 2013; Fernandes et al., 2015) and improving microorganisms' bioremediation potential 
through, for instance, exudation of organic compounds (Rocha et al., 2015). For instance, organic pollutants degradation was higher in the presence of plants (Fernandes et al., 2015). Hence, microorganisms should also be taken in consideration in phytoremediation processes.

This study aimed to evaluate the potential of the salt marsh plant, $P$. australis, and the microorganisms associated to its roots (rhizospheric microorganisms) to remove/degrade bezafibrate and paroxetine from estuarine medium. These compounds were chosen as representatives of extensively used pharmaceuticals. Controlled laboratory experiments included nutrients addition, to stimulate the microbial communities, increasing their abundance, and promote microorganisms' biodegradation conditions, and copper addition, to simulate the presence of different types of contaminants that can be found simultaneously in the estuaries. In fact, sites polluted with pharmaceuticals are also frequently polluted with other chemicals of different nature, like, for instance, petroleum hydrocarbons, pesticides and surfactants and also inorganic pollutants such as metals (Almeida et al., 2008). Several studies showed that the presence of organic and inorganic contaminants may influence the response of the salt marsh communities and, consequently, the phytoremediation process (e.g., Mucha et al., 2011; Oyetibo et al., 2017; Sayen et al., 2019). For instance, metal toxicity may affect organic pollutant degradation due to inhibition of microbial growth or interaction with enzymes directly involved in biodegradation or in general metabolism (Almeida et al., 2013). Moreover, metal-organic contaminant complexes can be formed, changing contaminants bioavailability and increasing or decreasing the uptake of either pollutant by the plants (Sayen et al., 2019). P. australis was chosen due to its potential of phytoremediation of different types of compounds, including pharmaceuticals as shown in previous studies (Sauvêtre \& Schröder, 2015; Fernandes et al., 2015). Experiments were carried out in elutriate solution, with or without sediment. Elutriate is a simple natural medium that allows to simulate the interactions among water, sediment and plant roots in estuarine environments.

\section{Materials and methods}

Materials and reagents

To prevent contamination, all sampling and labware materials were immersed in $20 \%(\mathrm{v} / \mathrm{v}) \mathrm{HNO}_{3}$ solution for at least $24 \mathrm{~h}$, rinsed several times with bi-deionised water (conductivity $<0.1 \mathrm{mS} / \mathrm{cm}$ ) and dried in an oven at $30^{\circ} \mathrm{C}$.

Paroxetine was obtained from Enzo Life Sciences. Bezafibrate, methanol, acetonitrile and formic acid $(98 \%)$ were acquired from Sigma-Aldrich. All remaining reagents were analytical grade or equivalent.

To prepare individual standard stock solutions of each pharmaceutical compound, suitable amounts of bezafibrate or paroxetine were dissolved in methanol. Standard working solutions were prepared from these individual standard stock solutions also in methanol. All these solutions were kept in amber vials and stored at $-20^{\circ} \mathrm{C}$.

\section{Sampling}

Plants ( $P$. australis), with similar size and age, and the respective rhizosediment (sediment in contact with plant roots, cubes with ca. $10 \mathrm{~cm} \times 10 \mathrm{~cm} \times 10 \mathrm{~cm}$ ) were collected in River Lima Estuary (41.689822, - 8.816289), in the north of Portugal, at low tide, in late March 2018 (first experiment) and in beginning of June 2018 (second experiment). The sampling location has moderate temperatures, maximum day temperature ca $15^{\circ} \mathrm{C}$ in March and ca. $18^{\circ} \mathrm{C}$ in June and at both time periods plant sizes were identical (between 50 and $60 \mathrm{~cm}$ height). This plant is commonly found in estuaries around the world and has shown a high potential for phytoremediation of diverse contaminants. Estuarine water was also collected simultaneously. In the laboratory, rhizosediment (separated from the plant roots) was homogenized, and large stones and remains of plant tissues were removed. A portion of sediment was kept at $-20^{\circ} \mathrm{C}$ for pharmaceutical analysis. Plants were left in estuarine water until experiments were assembled (within $24 \mathrm{~h}$ ).

Experiments assembly

Elutriates were prepared accordingly to the protocol of EPA (US EPA,1991), by mixing estuarine water and 
rhizosediment, in a proportion of $50 \mathrm{~g}$ of sediment with $200 \mathrm{ml}$ of estuarine water, per flask. The flasks were manually shaken to disintegrate soil clods and placed afterwards on a shaker for $30 \mathrm{~min}$. In total, 50 flasks were prepared and divided in two groups: one for experiments with sediment plus elutriate and another for experiments only with elutriate solution. For the first group, elutriate solution with sediment were transferred to $250 \mathrm{ml}$ glass flasks and left to settle until the beginning of the experiment. For the second group, flasks were left to settle during $24 \mathrm{~h}$. All elutriate solutions were then combined, filtrated through $0.45 \mu \mathrm{m}$ pore size filter (cellulose nitrate membrane, Millipore) and $200 \mathrm{ml}$ of elutriate solution were transferred to $250 \mathrm{ml}$ glass flasks $(200 \mathrm{ml}$ of elutriate solution per flask). The plants (P. australis) were washed with deionized water and 3 individual plants, randomly selected, were inserted in each flask. Plant roots were in permanent contact with the elutriate solution. When sediment was present, the plant roots were involved by it, but also in contact with elutriate solution as sediment was soaked in the elutriate solution. A similar number of flasks without plants was also prepared. This experimental approach is similar to that used previously in studies carried out by the authors (e.g., Fernandes et al., 2015, 2017).

For the first experiment, 5 different treatments (each in triplicate) were prepared: copper, bezafibrate, paroxetine, bezafibrate + copper and paroxetine + copper (Fig. S1 in Supplementary Material). For that, the flasks were doped with the respective contaminant: $100 \mu \mathrm{g} / \mathrm{l}$ of paroxetine $(20 \mu \mathrm{l}$ of a $1 \mathrm{~g} / \mathrm{l}$ stock solution for each $200 \mathrm{ml}$ of elutriate solution), $100 \mu \mathrm{g} / \mathrm{l}$ of bezafibrate $(20 \mu \mathrm{l}$ of a $1 \mathrm{~g} / \mathrm{l}$ stock solution for each $200 \mathrm{ml}$ of elutriate solution), and/or $100 \mathrm{mg} / \mathrm{l}$ of copper (chloride salt).

For the second experiment, 4 different treatments (each in triplicate) were prepared: bezafibrate, paroxetine, bezafibrate + nutrients and paroxetine + nutrients (Fig. S2 in Supplementary Material). For that, the flasks were doped with the respective contaminant, $100 \mu \mathrm{g} / \mathrm{l}$ of paroxetine or $100 \mu \mathrm{g} / \mathrm{l}$ of bezafibrate, without or with addition of nutrients. To have a suitable C:N:P (carbon:nitrogen:phosphorus) proportion, $40 \mathrm{mg} / \mathrm{l}$ of $\mathrm{NaCH}_{3} \mathrm{COO}, 4 \mathrm{mg} / \mathrm{l}$ of $\mathrm{KNO}_{3}$ and $1 \mathrm{mg} / \mathrm{l}$ of $\mathrm{KH}_{2} \mathrm{PO}_{4}$ were added, following an approach previously tested (Fernandes et al., 2015).

Before doping, $15 \mathrm{ml}$ elutriate solution was stored at $-20^{\circ} \mathrm{C}$ for pharmaceutical analysis.
For both experiments, each flask was wrapped in aluminum foil to avoid photodegradation. The flasks were exposed to natural day: night regime with natural sunlight for 1 week (7 days) in a protected area of the laboratory, which has a glass roof, allowing the penetration of sunlight and exposer to the natural photoperiod regime. Temperature varied between 14 and $20^{\circ} \mathrm{C}$.

For each experiment, during the week, a second (at the third day) and a third (at the fifth day) doping of $100 \mu \mathrm{g} / \mathrm{l}$ of bezafibrate or paroxetine was performed to simulate a continuous input of pollutants, and to evaluate the behavior of the plant exposed to the pharmaceuticals during the whole week of the experiment. Therefore, the total doping was $300 \mu \mathrm{g} / \mathrm{l}$ for each pharmaceutical compound. This is a much higher concentration than that commonly found in rivers and WWTP effluents (Pereira et al., 2014; Silva et al., 2014) but it was chosen to simulate a worst-case scenario, with a significant contamination of the water reaching the estuarine environment, exposing the plant to an extreme situation.

Copper was added to test if the presence of other contaminants would influence the phytoremediation potential of the plant and the respective rhizospheric microbial community. For instance, copper has shown to interfere with hydrocarbons degradation (Almeida et al., 2008, 2009). The metal was added only at the beginning of the experiment, simultaneously with the pharmaceutical compound, since it is an inorganic compound that, contrary to organic contaminants, is not degraded. The concentration chosen was higher than that tested before (Fernandes et al., 2017) to simulate also a worst-case scenario in which a much higher proportion of metal relative to pharmaceutical compounds is normally present.

A timeframe of 7 days was selected accordingly to previous studies (Rocha et al., 2015), as longer time periods in the type of flasks used ( $250 \mathrm{ml}$ glass flasks) would result in plant physiological stress, which could influence experimental results (Rocha et al., 2015).

During the experimental time period, no significant evapotranspiration was observed with solution levels being identical at the end of the experiments and no need to compensate solution levels.

Removal efficiency of bezafibrate and paroxetine after the experiments was evaluated by measuring the pharmaceutical compounds in elutriate solutions and in sediments when present. Therefore, at the end of 
each experiment, $15 \mathrm{ml}$ of elutriate samples were collected from each flask and stored at $-20^{\circ} \mathrm{C}$ for pharmaceutical compounds analysis. Sediment samples, when present, were collected from each flask and stored at $-20^{\circ} \mathrm{C}$ for lyophilization prior to pharmaceutical compounds analysis. Bezafibrate and paroxetine were not determined in plant tissues due to lack of validated analytical methodology. $\mathrm{pH}$ was immediately determined in every flask solution.

\section{Pharmaceutical compounds analysis}

For sediments, two sequential extractions were carried out with a solution of methanol/ammonia $(95: 5, \mathrm{v} / \mathrm{v})$ in an ultrasonic bath (Transsonic 460/H). The procedure was based on a previously optimized methodology (Talaya, 2015). The supernatants were combined and evaporated until dryness under a $\mathrm{N}_{2}$ flux. The residue was then dissolved in water/formic acid (99:1, v/v) solution. The samples were stored at $-20^{\circ} \mathrm{C}$ until analysis. Before analysis, one of the triplicates was divided and one part was doped with bezafibrate and paroxetine to check extraction recovery (which were $88 \pm 32 \%$ for bezafibrate and $56 \pm 26 \%$ for paroxetine as this was a muddy sediment with a complex matrix mainly due to the high amount of organic matter and small grain size which can interfere with compound removal).

For elutriate solutions, solid-phase extraction (SPE) was carried out with cartridges Oasis MCX (3 ml, $3 \mathrm{cc}$ ) from Waters Corporation (Millford, MA, USA) following a previously optimized methodology (Sousa, 2014). For SPE elution, for bezafibrate a methanol/formic acid (96:4, v/v) solution was used, whereas for paroxetine elution was carried out with a methanol/ammonia (95:5, v/v) solution. SPE extracts were then evaporated by $\mathrm{N}_{2}$ flux. The residue was dissolved in water/formic acid (99:1, v/v) solution. The samples were stored at $-20^{\circ} \mathrm{C}$ until analysis. To check SPE recoveries, aqueous standard solutions and elutriate solutions doped with known amounts of each pharmaceutical were subjected to SPE.

Both sediment and elutriate solution extracts were analyzed by high-performance liquid chromatography, in a Beckman Coulter equipment (HPLC-system gold) with a diode array detector (DAD) using a previously optimized methodology (Sousa, 2014). The column was a $150 \mathrm{~mm} \times 4.6 \mathrm{~mm} \mathrm{C18}$ Kinetex column (Phenomenex, UK). Two mobile phases (water/formic acid, 99:1, v/v) and acetonitrile (both always degassed for $15 \mathrm{~min}$ in the ultrasound) were used.

An external calibration with aqueous standard solutions of bezafibrate and paroxetine was carried out daily to quantify each pharmaceutical compound. For this, pharmaceutical standard solutions were prepared every day from working standard solutions of each individual pharmaceutical compound with concentrations between 0.1 and $5 \mathrm{mg} / \mathrm{l}$. These solutions were prepared immediately before analysis in a mixture of methanol and HPLC mobile phase (25:75; $\mathrm{v} / \mathrm{v})$.

Results from doped samples along the different analytical steps showed recoveries of ca. $85 \pm 11 \%$ for bezafibrate and of ca. $50 \pm 15 \%$ for paroxetine. All the results obtained for paroxetine were corrected for this recovery, which was due to low recovery from muddy sediments and from the SPE cartridges used. For bezafibrate, results were considered as obtained, without correction, as they were within the acceptable recovery range of $80-120 \%$. Limits of detection for bezafibrate and paroxetine in solution (considering the SPE step) and in sediment were $5 \mu \mathrm{g} / \mathrm{l}$ and $0.05 \mu \mathrm{g} / \mathrm{g}$, respectively.

Data analysis

Elutriate and sediment samples of the different treatments were analyzed for the respective compound. Each sample was treated independently, being the mean and standard deviation of the three experimental replicates calculated.

For pharmaceutical concentrations, significant $(P<0.05)$ differences among samples were evaluated through a parametric one-way analysis of variance (ANOVA) followed by Tukey pair wise comparisons test.

\section{Results and discussion}

In the flasks with elutriate, plant and sediment, the roots of some plants were darker (almost black), which may indicate the beginning of the systems decomposition. The plants appeared to be on stress probably due to the experimental conditions. This was also observed in other studies (Carvalho et al., 2012; Fernandes et al., 2015) for this type of experiment and 
was probably related with anoxic processes in sediments. In the flasks only with elutriate solution, plants were apparently healthier, without dark spots in their roots. When nutrients were added, the roots of the plants appeared healthier and the systems were in better conditions, similar to what was observed before (Fernandes et al., 2015). This was observed either in the presence or absence of either pollutant.

In Table 1, the values of $\mathrm{pH}$ in elutriate solutions are presented.

In general, there were no significant differences among treatments for each medium. In the presence of plants, $\mathrm{pH}$ was slightly lower. This has been observed before and can be related with plant exudation (Almeida et al., 2008). Plants are known to exude compounds, namely low molecular organic acids (e.g., Rocha et al., 2015) which can contribute for a decrease of the medium $\mathrm{pH}$.

In the presence of $\mathrm{Cu}, \mathrm{pH}$ was lower, due to the addition of the metal salt. However, this was only observed in the absence of sediment, as when sediment was present it acted like a buffer maintaining the $\mathrm{pH}$ at neutral values.

Phragmites australis phytoremediation potential for bezafibrate

Considering bezafibrate in elutriate solution (Fig. 1), it is possible to verify that this compound was partially removed.

In the absence of plants and sediment (El), elutriate solution had the higher concentration of bezafibrate in solution (ca. $0.23 \mathrm{mg} / \mathrm{l}$ ), which corresponds to a removal of $23 \%$ of the bezafibrate added $(0.3 \mathrm{mg} / \mathrm{l})$. Since the elutriate solution was filtered, a high number of microorganisms is not expected. Therefore, this percentage of removal is probably related with abiotic factors. Yang et al. (2011) reported that the most used methods of water sample preparation involve separating solid phases from water using membrane filters (e.g., pore size of $0.45 \mu \mathrm{m}$ ). However, the "dissolved" phase obtained includes complex fractions such as colloids of different sizes that present a large surface site density and large surface area. Thus colloids may present an enhanced sorption affinity for organic compounds such as pharmaceuticals (Yang et al., 2011). In the case of this study, a membrane filter of $0.45 \mu \mathrm{m}$ was used to filter the elutriate, so bezafibrate could have been aggregated to colloidal matter. Another abiotic process is photodegradation. Trovó et al. (2008) reported that solar radiation may favor the degradation of bezafibrate; however, the flasks were wrapped in aluminum foil therefore significant photodegradation of the compound was not expected.

In the presence of the plants $(\mathrm{El}+\mathrm{Pl})$, the concentration of bezafibrate was ca. $0.18 \mathrm{mg} / \mathrm{l}$, corresponding to a removal efficiency of $42 \%$, indicating that the plant increased the removal of the compound, with significant differences $(P<0.05)$ being observed relatively to absence of the plant. The diffusion process of organic compounds into plants depends on their concentration, water solubility and hydrophobicity (expressed by $\log K_{\mathrm{OW}}$ ) (Dordio \& Carvalho, 2013). Organic compounds with moderate hydrophobicity $\left(0.5<\log K_{\mathrm{OW}}<3\right)$ are considered easily taken up by the plants, while extremely hydrophobic compounds ( $\log K_{\mathrm{OW}}>3$ ) are tightly bound to soil organic matter, such as plant and animal detritus (Carvalho et al., 2012). Bezafibrate has a value of $\log$ $K_{\mathrm{OW}}$ of 4.25 , so, probably plant uptake (when no

Table 1 Values of $\mathrm{pH}$ for each treatment in both experiments (media and standard deviation, $n=3$ )

\begin{tabular}{lllll}
\hline & El & El + Sed & El + Pl & El + Sed + Pl \\
\hline Initial elutriate & 7.8 & - & - & - \\
Bzf & 7.3 & $7.42 \pm 0.02$ & $6.9 \pm 0.2$ & $7.12 \pm 0.06$ \\
Prx & 7.4 & $7.34 \pm 0.04$ & $7.0 \pm 0.1$ & $7.0 \pm 0.1$ \\
Bzf + Nut & 7.3 & $6.6 \pm 0.1$ & $6.17 \pm 0.06$ & $6.5 \pm 0.1$ \\
Prx + Nut & 7.6 & $7.1 \pm 0.2$ & $7.02 \pm 0.07$ & $7.0 \pm 0.1$ \\
$\mathrm{Cu}+$ Bzf & 5.6 & $7.2 \pm 0.1$ & $6.04 \pm 0.04$ & $6.83 \pm 0.07$ \\
$\mathrm{Cu}+$ Prx & 5.6 & $7.30 \pm 0.08$ & $6.00 \pm 0.02$ & $6.82 \pm 0.08$ \\
\hline
\end{tabular}

$E l$ elutriate, $E l+P l$ elutriate and plants, $E l+S e d$ elutriate and sediments, $E l+P l+S e d$ elutriate, plants and sediments 


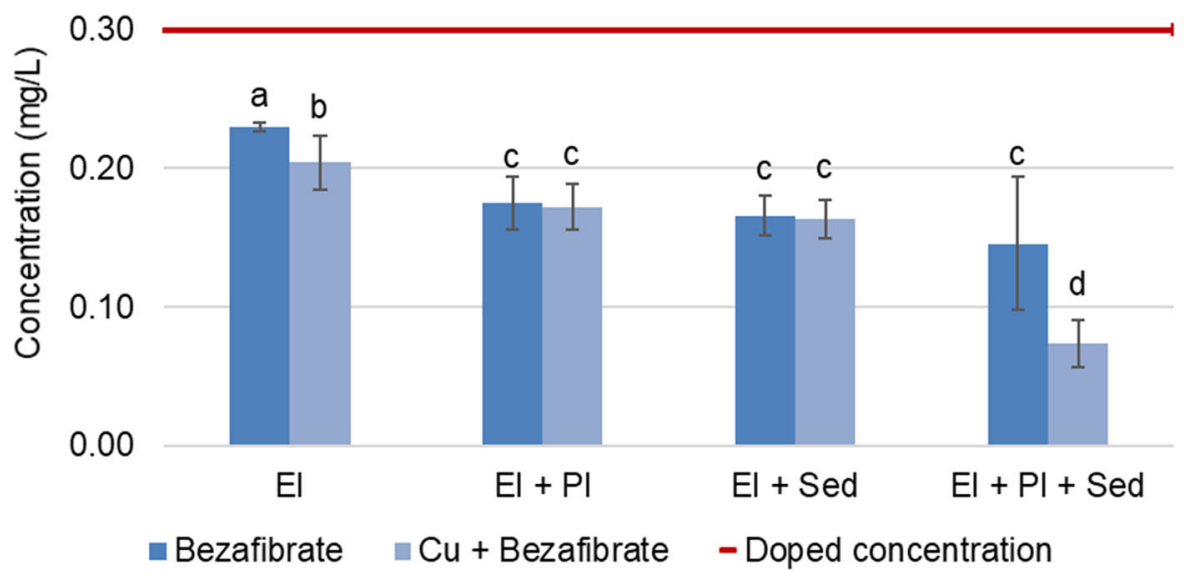

Fig. 1 Concentration of bezafibrate in elutriate solution (media and standard deviation, $n=3$ ) of the different treatments in the absence and in the presence of copper. $E l$ elutriate, $E l+P l$ elutriate and plants, $E l+S e d$ elutriate and sediments, $E l+$

sediment was present) did not occurred, although $K_{\text {ow }}$ is only one of the factor to influence chemical uptake by plants, and bezafibrate removal was probably due to adsorption to plant tissues (namely plant roots). However, it was not possible to determined bezafibrate in plant tissues.

When sediments were present in the absence of plants, a reduction of about $45 \%$ of bezafibrate was observed, indicating that the compound was probably retained in the sediment or degrade by the native estuarine microbial community present in the sediment. Significant differences $(P<0.05)$ were observed relatively to absence of sediment. Organic compounds are known to adsorb to sediment and the high $K_{\text {ow }}$ of bezafibrate would promote it. So, removal from elutriate could be due to adsorption to sediment. However, some studies showed low adsorption capacity of bezafibrate (Jelic et al., 2011; Tang et al., 2014). Adsorption capacity can be influenced by $\mathrm{pH}$, and previous studies showed that, at neutral $\mathrm{pH}$, the adsorption capacity to solid particles of bezafibrate is low due to electrostatic repulsive forces exerted by the negative charge of the compound (Duarte et al., 2019). In the current study, concentration of bezafibrate in sediments was below detection limit $\left(\mathrm{LOD}_{\text {Bezafibrate- }}\right.$ $=0.05 \mu \mathrm{g} / \mathrm{g}$ ) (no bezafibrate was detected in sediment collected in the estuary and used for the experiments). So bezafibrate removal was possibly due to degradation of the drug in the sediment by the rhizospheric microorganisms that were present, as if all bezafibrate concentration removed from the
$P l+S e d$ elutriate, plants and sediments. Red line indicates the doped value. Different letters indicate statistically significant differences $(P<0.05)$

elutriate solution would be adsorbed into the sediment, the analytical methodology would allow its detection in this medium. Biodegradation of bezafibrate by microorganisms present in an estuarine sediment has been reported (Duarte et al., 2019), although the degradation occurred under optimal laboratory conditions.

When both plant and sediments were present $(\mathrm{El}+\mathrm{Pl}+\mathrm{Sed})$, the concentration of bezafibrate halved ca. $0.15 \mathrm{mg} / \mathrm{l}$ corresponding to ca. $48 \%$ of removal, a value statistically identical $(P>0.05)$ to that observed in the absence of plants. So, in the presence of sediment, plants did not seem to have a significant role in bezafibrate removal, either because the compound was not available for plant uptake or no adsorption to plant roots occurred.

\section{Effect of nutrients addition}

In the absence of nutrients, results were in general identical to those previously obtained (Fig. 2). Similar abiotic removals percentages (ca. 23\%) were observed. The presence of the plant, in the absence of sediment, decreased once again the concentration of bezafibrate in solution (ca. 33\%), although removal of the compound was slightly lower than in the first experiment. In the presence of sediment, without plants removal was ca. $60 \%$ and in the presence of plants removal of bezafibrate was ca. $47 \%$, but there were no significant differences among bezafibrate concentrations in solution. The fact that new plants 


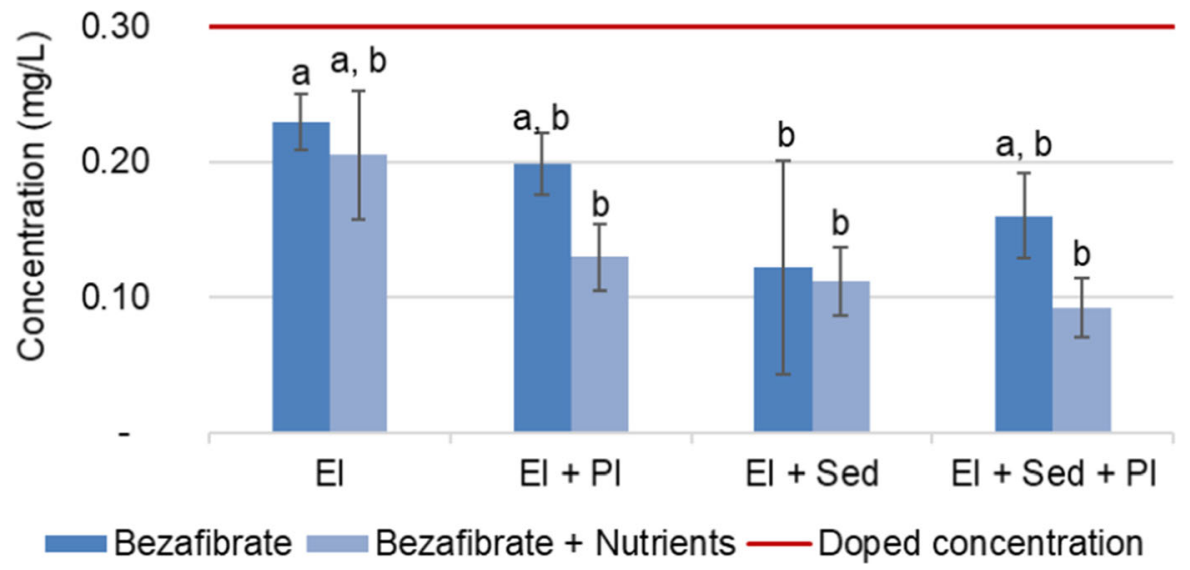

Fig. 2 Concentration of bezafibrate in elutriate solution (media and standard deviation, $n=3$ ) of the different treatments with or without addition of nutrients. $E l$ elutriate, $E l+P l$ elutriate and plants, $E l+S e d$ elutriate and sediments, $E l+P l+S e d$

and sediments were collected and a new elutriate solution was prepared justifies these differences in removal percentages relatively to the first experiment. In fact, plants, sediments and estuarine water were collected in different time periods, one in March and another in June and some seasonal differences could be expected. However, a low temperature variability (varied between 15 and $18^{\circ} \mathrm{C}$ ) was observed. Moreover, similar size plants were collected at both time periods (between 50 and $60 \mathrm{~cm}$ height) and similar experimental conditions were used. So, one can consider that obtained results were not significantly affect by seasonality.

When nutrients were added, the concentration of bezafibrate in elutriate solution in the presence of plants was lower than without nutrients, with removals up to $70 \%$. This was observed either in the absence or in the presence of sediment. This reveals that nutrients had a positive effect in the removal of bezafibrate by the plants. The presence of nutrients has been reported to be essential for plant preservation and survival, keeping the systems in good operating conditions, ensuring aerobic degradation (Fernandes et al., 2015). In addition, in the present study in the systems with nutrients, plants looked healthier at the end of experiment. However, more research is needed to fully elucidate the mechanisms involved in the positive effect of nutrition addition. Nutrient addition could also increase plant biomass, leading to higher pollutant removal, but in these short-term experiments (7 days), biomass increase is not expected. elutriate, plants and sediments. Red line indicates the doped value. Different letters indicate statistically significant differences $(P<0.05)$

On the other hand, in the absence of plants, nutrients had no effect on bezafibrate removal from elutriate solution, so nutrients did not stimulate the microbial communities. The addition of nutrients to stimulate the biodegradation of organic contaminants is a common practice in bioremediation technologies (e.g., Almeida et al., 2013), but in some cases it might not work or it might even have negative effects decreasing the biodegradation (Fernandes et al., 2015; Thiele-Bruhn \& Aust, 2004). However, considering bezafibrate levels in sediments (Fig. 3), nutrients clearly stimulated the rhizospheric microorganisms, but only in the absence of plants. Contrarily to the first experiment, bezafibrate was detected in all sediments used in the experiment. These results also indicate that sorption to sediments had a significant effect on the removal of the compound from elutriate solution.

\section{Effect of copper addition}

In general, copper did not affect bezafibrate removal from elutriate solution (statistically identical results, $P>0.05)$, except for the system with elutriate + plant + sediments (Fig. 1). In this case, a significantly higher $(P>0.05)$ removal (ca. 75\%) was observed in the presence of the metal. This indicates that the presence of copper might influence the retention or degradation of the compounds when all the components of the salt marsh estuarine system (water, plants and sediment) are present. Almeida et al. (2009) reported that some organic pollutants may 


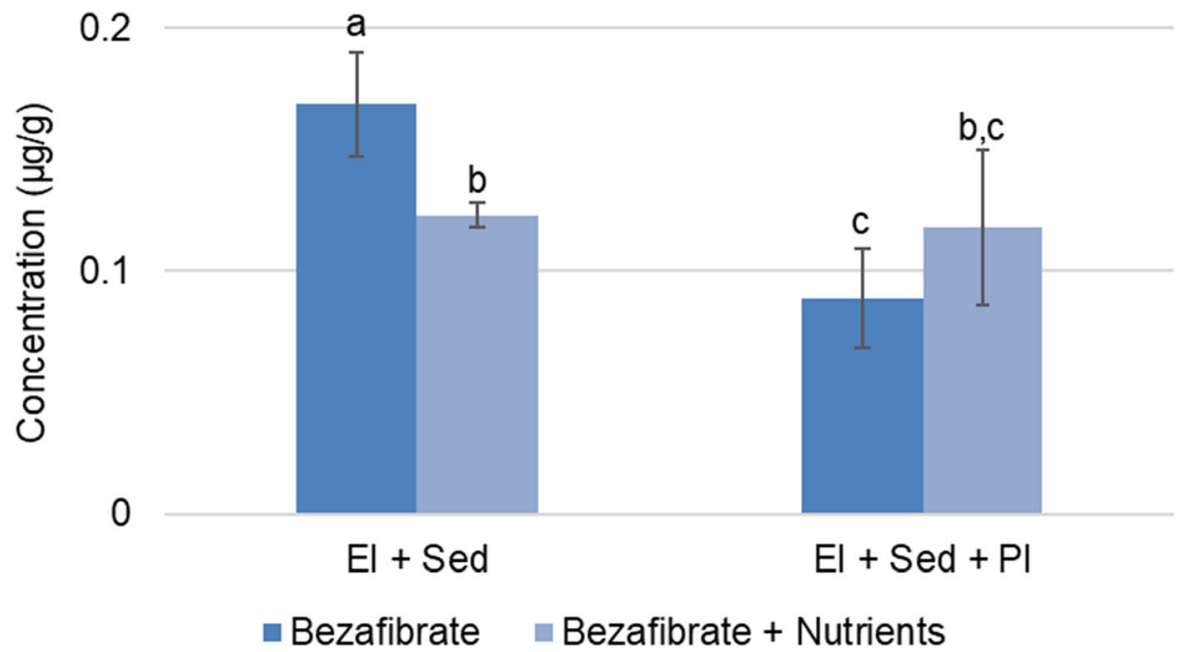

Fig. 3 Concentration of bezafibrate in sediment (media and standard deviation, $n=3$ ) of the different treatments with or without addition of nutrients: $E l+S e d$ elutriate and sediments,

positively influence the phytoremediation of copper by Halimione portulacoides, so copper can also promote bezafibrate retention/degradation. Some studies have, however, indicated that metals, namely copper, can inhibit biodegradation, for instance, of hydrocarbons (Almeida et al., 2013). But this depended on medium composition which conditioned metal bioavailability and it was observed only for sandy sediment and not for muddy sediment, like the one used in the present experiments. So, in the present study copper promoted bezafibrate removal. No bezafibrate was also detected in sediment preventing evaluating adsorption role on these processes and more research is needed to clarify the mechanisms by which the metal is promoting bezafibrate removal.

Phragmites australis phytoremediation potential for paroxetine

Considering paroxetine in elutriate solution (Fig. 4), all treatments showed removals of paroxetine of ca. $50 \%$ or more. In the absence of plants and sediment (El), after a week, paroxetine in elutriate solution had a concentration of ca. $0.16 \mathrm{mg} / \mathrm{l}$, corresponding to a removal of $47 \%$. As mentioned before for bezafibrate, this percentage of removal may due to adsorption to colloids, as photodegradation is not expected.

In the presence of plants $(\mathrm{El}+\mathrm{Pl})$, comparing with the treatment with only elutriate, the concentration of
$E l+P l+$ Sed elutriate, plants and sediments. Different letters indicate statistically significant differences $(P<0.05)$

paroxetine decreases to ca. $0.12 \mathrm{mg} / \mathrm{l}$ which corresponds to a percentage of removal of $57 \%$, although differences were not statistically significant $(P>0.05)$. paroxetine could both adsorb to plant roots and be taken up by the plant, since Phragmites australis has been reported to uptake carbamazepine, an antiepileptic pharmaceutical (Sauvêtre \& Schröder, 2015). Studies showed that the uptake of organic compounds by $P$. australis is related to the $\log K_{\mathrm{OW}}$ and $\mathrm{p} K_{\mathrm{a}}$ of the compound, being higher with compounds where $\log K_{\mathrm{OW}}$ is between 1 and 3 (Schröder et al., 2008). Values of $K_{\text {ow }}$ of paroxetine depend on the $\mathrm{pH}: \log K_{\mathrm{ow}}=1.35$ for $\mathrm{pH} 7$ (Cunningham et al., 2004) and $\log K_{\mathrm{ow}}=3.95$ for $\mathrm{pH}$ higher than 8 (Brown et al., 2015). In this case, paroxetine has a value of $K_{\text {Ow }}$ of 1.23 , so it can be easily taken up by the plants. As for bezafibrate, paroxetine was not measured in plant tissues.

In the presence of sediments $(\mathrm{El}+\mathrm{Sed})$, removal of paroxetine from solution increased significantly $(P<0.05)$, up to $82 \%$. In this case, both adsorption to colloids of the elutriate and sorption to the sediments and plant residues present in the sediments must be taken into account. Although $K_{\text {ow }}$ is not high, paroxetine adsorption to sediment particles or cells has been reported (Kwon \& Armbrust, 2008; Duarte et al., 2019) due to combination of organic carbon partition and ionic bounding. The levels of paroxetine found in sediment, between 0.10 and $0.20 \mu \mathrm{g} / \mathrm{g}$, clearly show 


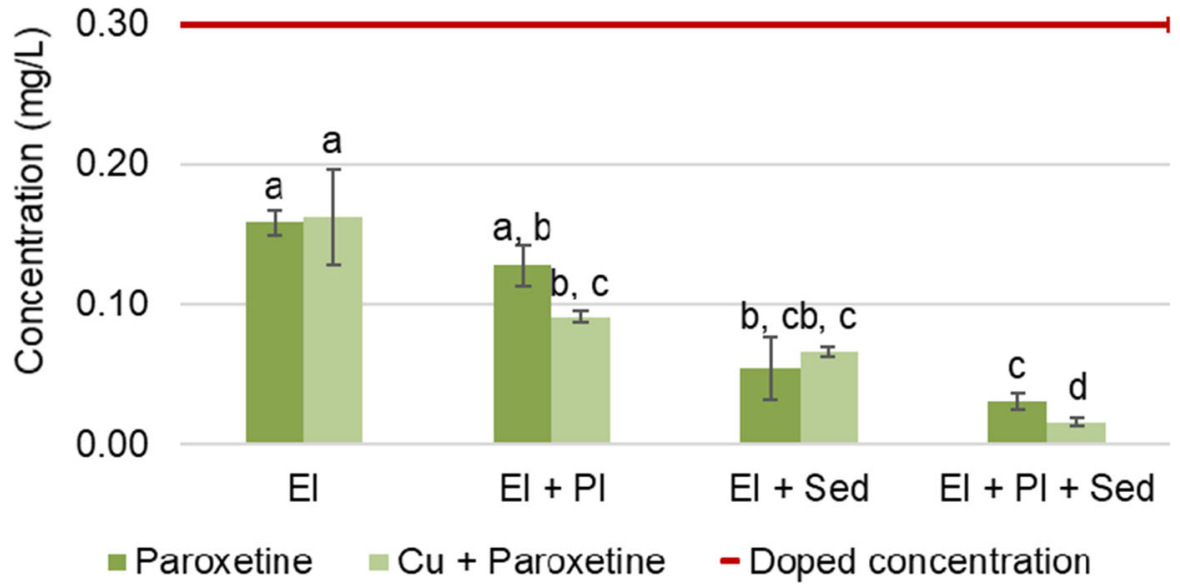

Fig. 4 Concentration of paroxetine in elutriate solution (media and standard deviation, $n=3$ ) of the different treatments, in the absence and presence of copper. $E l$ elutriate, $E l+\mathrm{Pl}$ elutriate and plants, $E l+S e d$ elutriate and sediments, $E l+P l+S e d$

the adsorption of the compound, indicating it had a significant effect on the removal of the compound from elutriate solution (Fig. 5).

Moreover, microbial degradation by native microorganisms present in the rhizosediment should be considered as this compound can be biologically degraded, namely by microorganisms present in estuarine sediment (Duarte et al., 2019). In fact, there are several studies reporting the potential of microorganisms to degrade or remove different types of contaminants, including pharmaceuticals (Yu et al., elutriate, plants and sediments. Red line indicates the doped value. Different letters indicate statistically significant differences $(P<0.05)$

2006) and since rhizosediments present a large variety of microorganisms, the degradation of the compound by the microorganisms must be taken into account. In the present case, considering the amount of paroxetine added to the system, concentrations of paroxetine in the sediment clearly indicates that a part of the compound was biologically degraded.

Considering the treatment with both sediment and plant $(\mathrm{El}+\mathrm{Pl}+\mathrm{Sed})$, a removal of paroxetine from solution of ca. $90 \%$ was observed, being the concentration in solution statistically identical $(P>0.05)$ to

\subsection{0}

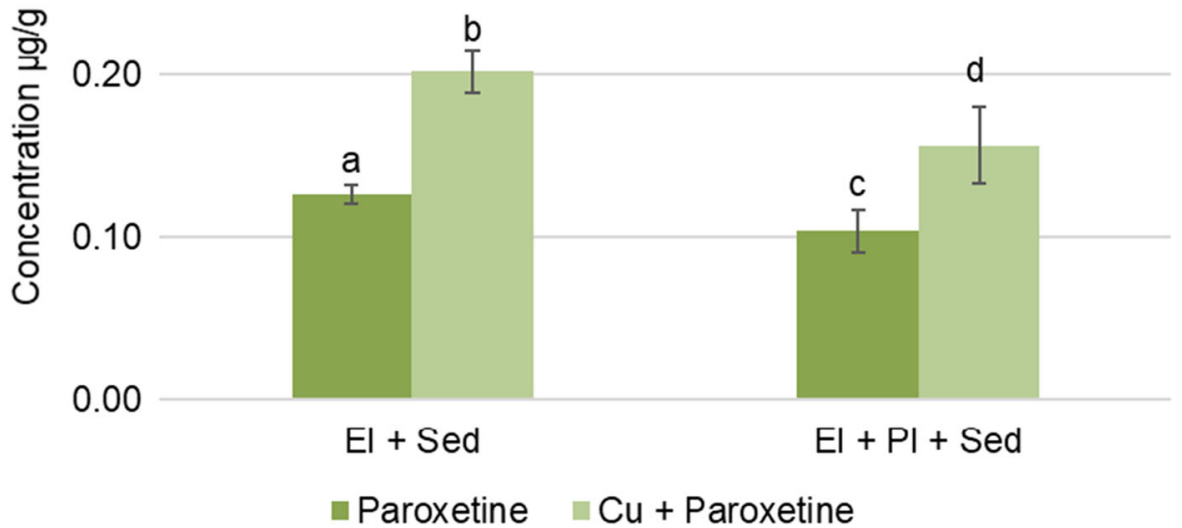

Fig. 5 Concentration of paroxetine in sediment (media and standard deviation, $n=3$ ) of the different treatments in the absence and in the presence of copper. $E l+S e d$ elutriate and sediments, $E l+P l+S e d$ elutriate, plants and sediments. Different letters indicate statistically significant differences $(P<0.05)$ 
Fig. 6 Concentration of paroxetine in elutriate solution (media and standard deviation, $n=3$ ) of the different treatments without or with addition of nutrients. $E l$ elutriate, $E l+P l$ elutriate and plants, $E l+$ Sed elutriate and sediments, $\mathrm{El}+\mathrm{Pl}+\mathrm{Sed}$ elutriate, plants and sediments. Red line indicates the doped value. Different letters indicate statistically significant differences $(P<0.05)$
0.30

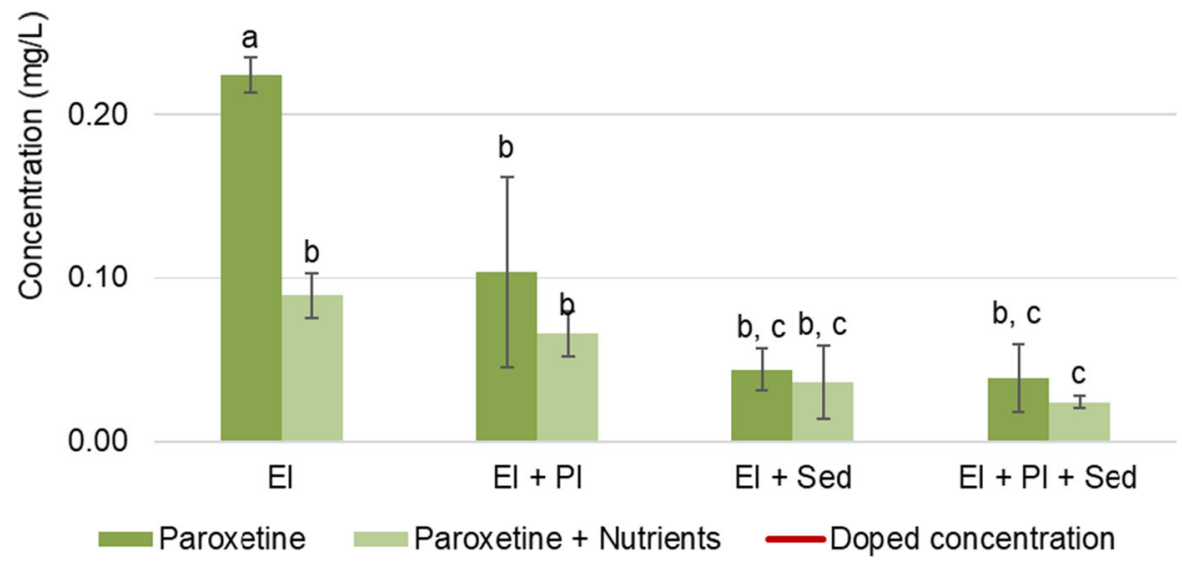

the one in the treatment with sediment but without plant. Considering that in sediment there was a slightly lower amount of paroxetine when plants were present, results indicate that the plant contribute for the removal of paroxetine even in the presence of sediments.

\section{Effect of nutrients addition}

In the absence of nutrients, a low removal percentage (ca. 24\%) was observed in the flasks with only elutriate (Fig. 6). Once more, adsorption to colloids and abiotic factors must not be excluded. In the remaining flasks without nutrients addition, the removals of paroxetine were similar to the previous experiment. Once again, the new plants and sediments collected and the new elutriate solution justify the slight differences but, as mentioned above, one can consider that seasonality did not influenced significantly the results obtained.

In the presence of nutrients, the concentration of paroxetine in solution was lower; however, the differences were not significant $(P>0.05)$, except for the treatment with only elutriate which was significantly lower $(P<0.05)$ than without nutrient. Filtration reduces significantly the presence of microorganisms in the medium; however, the presence

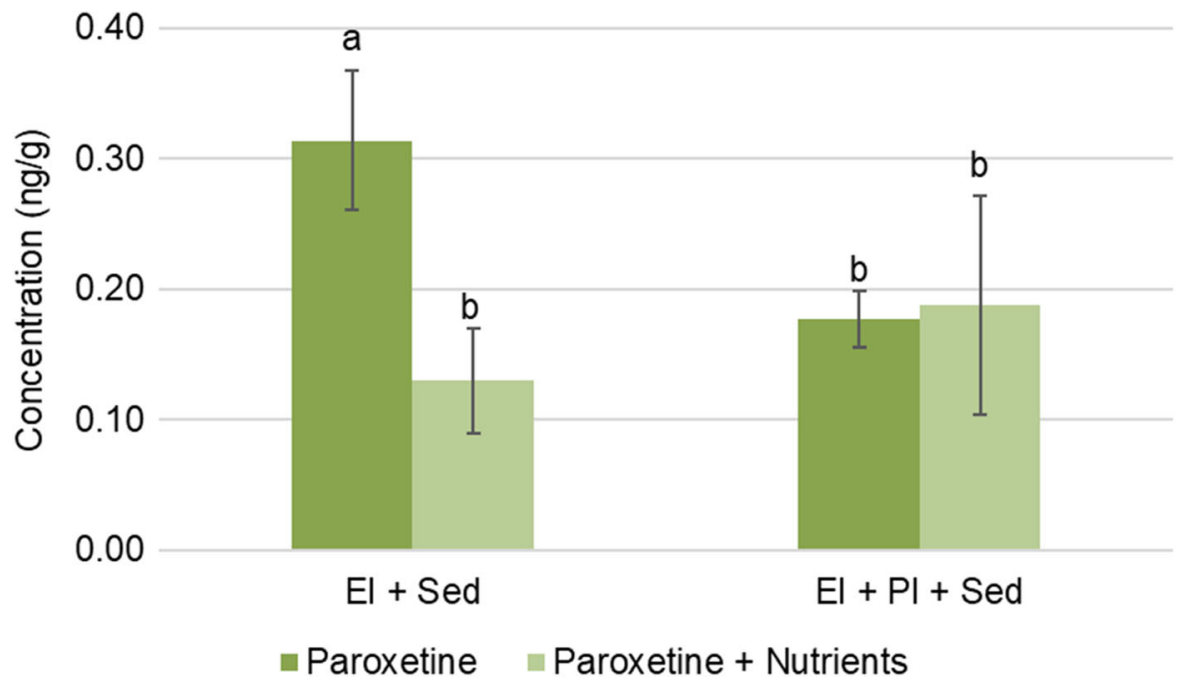

Fig. 7 Concentration of paroxetine in sediment (media and standard deviation, $n=3$ ) of the different treatments without or with addition of nutrients. $\mathrm{El}+\mathrm{Sed}$ elutriate and sediments,
$E l+P l+S e d$ elutriate, plants and sediments. Different letters indicate statistically significant differences $(P<0.05)$ 
of nutrients in the medium may have stimulated the reduced number of microorganisms leading to their proliferation and consequent degradation of the pharmaceutical.

Nutrients also stimulate the microorganisms present in the sediment, as paroxetine concentration clearly decrease when nutrients were added to the medium, although this was only significant $(P<0.05)$ in the absence of plants (Fig. 7). In the presence of plants, paroxetine levels in sediment were statistically identical $(P>0.05)$ either with or without addition of nutrients, indicating that plants were providing all the necessary nutritional conditions, probably due to plants exudation.

\section{Effect of copper addition}

Regarding the treatment with paroxetine and copper (Fig. 4), no significant differences $(P>0.05)$ relatively to the absence of copper were observed when plants were not present but in the presence of plants paroxetine removal from solution increased, although only significantly $(P<0.05)$ in the presence of sediment.

Paroxetine concentration in sediments on the other hand indicate that, the presence of copper promoted a higher retention of the compound in the sediment, with significant differences $(P<0.05)$ (Fig. 5). So, copper might promote paroxetine removal from the aqueous phase but interfere with paroxetine biodegradation in sediments. So, simultaneous presence of the metal and paroxetine might affect the removal/degradation of the pharmaceutical in estuarine areas and more research is needed to highlight the mechanisms behind this stimulation. Copper can be either toxic or a nutrient to both plants and microorganisms which can interfere or promote compounds removal/degradation. In the present study, plants did not shown any visual toxicity signs due to the presence of copper and were in fact able to accumulate a high amount of copper, even in their upper ground tissues (results not shown). Therefore, $\mathrm{Cu}$ was probably not toxic to the plants in the current experimental conditions.

\section{Conclusion}

Overall, this study shows that the salt marsh plant $P$. australis and particularly its rhizosediments and the microorganisms associated have potential to remove the selected pharmaceutical compounds from estuarine environment, either through adsorption to sediment or eventually by degradation of these contaminants, a feature that requires more research.

This study also shows that the estuarine environment (plant, sediments and water) have a natural potential to remove (retaining and degrading) emerging contaminants, so it is important to enhance this remediation, which can be achieved by a proper nutritional state.

Results also highlight the fact that the simultaneous presence of different contaminants can affect the removal/degradation of pharmaceutical compounds, although the effect might depend on the pharmaceutical type. Therefore, further research is needed on the environmental remediation of the different emerging pollutants, as well as their interaction with other chemicals.

Acknowledgements This research was partially supported by national funds through FCT-Foundation for Science and Technology within the scope of UIDB/04423/2020 and UIDP/ $04423 / 2020$ and by the structured Program of R\&D\&I INNOVMAR-Innovation and Sustainability in the Management and Exploitation of Marine Resources, reference NORTE-01-0145-FEDER-000035, namely within the Research Line ECOSERVICES (Assessing the environmental quality, vulnerability and risks for the sustainable management of the NW coast natural resources and ecosystem services in a changing world) within the R\&D Institution CIIMAR (Interdisciplinary Centre of Marine and Environmental Research), supported by the Northern Regional Operational Programme (NORTE2020), through the European Regional Development Fund (ERDF).

\section{References}

Almeida, C. M. R., A. P. Mucha, M. F. C. Delgado, M. Isabel Caçador, A. A. Bordalo \& M. T. S. D. Vasconcelos, 2008. Can PAHs influence $\mathrm{Cu}$ accumulation by salt marsh plants? Marine Environmental Research 66: 311-318.

Almeida, C. M. R., A. Claúdia Dias, A. P. Mucha, A. A. Bordalo \& M. T. S. D. Vasconcelos, 2009. Study of the influence of different organic pollutants on $\mathrm{Cu}$ accumulation by $\mathrm{Hal}$ imione portulacoides. Estuarine, Coastal and Shelf Science 85: 627-632.

Almeida, R., A. P. Mucha, C. Teixeira, A. A. Bordalo \& C. M. R. Almeida, 2013. Biodegradation of petroleum hydrocarbons in estuarine sediments: metal influence. Biodegradation 24: 111-123.

Aminot, Y., K. Le Menach, P. Pardon, H. Etcheber \& H. Budzinski, 2016. Inputs and seasonal removal of 
pharmaceuticals in the estuarine Garonne River. Marine Chemistry 185: 3-11.

Bai, X., A. Lutz, R. Carroll, K. Keteles, K. Dahlin, M. Murphy \& D. Nguyen, 2018. Occurrence, distribution, and seasonality of emerging contaminants in urban watersheds. Chemosphere 200: 133-142.

Barbosa, M. O., A. R. Ribeiro, N. Ratola, E. Hain, V. Homem, M. F. R. Pereira, L. Blaney \& A. M. T. Silva, 2018. Spatial and seasonal occurrence of micropollutants in four Portuguese rivers and a case study for fluorescence excitationemission matrices. Science of the Total Environment 644: 1128-1140.

Brown, A. K., J. K. Challis, C. S. Wong \& M. L. Hanson, 2015. Selective serotonin reuptake inhibitors and $\beta$-blocker transformation products may not pose a significant risk of toxicity to aquatic organisms in wastewater effluent-dominated receiving waters. Integrated Environmental Assessment and Management 11: 618-639.

Cantwell, M. G., D. R. Katz, J. C. Sullivan, D. Shapley, J. Lipscomb, J. Epstein, A. R. Juhl, C. Knudson \& G. D. O'Mullan, 2018. Spatial patterns of pharmaceuticals and wastewater tracers in the Hudson River Estuary. Water Research 137: 335-343.

Carvalho, P. N., M. C. P. Basto \& C. M. R. Almeida, 2012. Potential of Phragmites australis for the removal of veterinary pharmaceuticals from aquatic media. Bioresource Technology 116: 497-501.

Cunningham, V. L., D. J. C. Constable \& R. E. Hannah, 2004. Environmental risk assessment of paroxetine. Environmental Science \& Technology 38: 3351-3359.

da Silva, M. N., A. P. Mucha, A. C. Rocha, C. Silva, C. Carli, C. R. Gomes \& C. M. R. Almeida, 2014. Evaluation of the ability of two plants for the phytoremediation of $\mathrm{Cd}$ in salt marshes. Estuarine, Coastal and Shelf Science 141: 78-84.

Dordio, A. V. \& A. J. P. Carvalho, 2013. Organic xenobiotics removal in constructed wetlands, with emphasis on the importance of the support matrix. Journal of Hazardous Materials 252-253: 272-292.

Duarte, P., C. M. R. Almeida, J. P. Fernandes, D. Morais, M. Lino, C. R. Gomes, M. F. Carvalho \& A. P. Mucha, 2019. Bioremediation of bezafibrate and paroxetine by microorganisms from estuarine sediment and activated sludge of an associated wastewater treatment plant. Science of the Total Environment 655: 796-806.

Fernandes, J. P., C. M. R. Almeida, M. C. P. Basto \& A. P. Mucha, 2015. Response of a salt marsh microbial community to antibiotic contamination. Science of the Total Environment 532: 301-308.

Fernandes, J. P., C. M. R. Almeida, F. Andreotti, L. Barros, T. Almeida \& A. P. Mucha, 2017. Response of microbial communities colonizing salt marsh plants rhizosphere to copper oxide nanoparticles contamination and its implications for phytoremediation processes. Science of the Total Environment 581-582: 801-810.

Jelic, A., M. Gros, A. Ginebreda, R. Cespedes-Sánchez, F. Ventura, M. Petrovic \& D. Barcelo, 2011. Occurrence, partition and removal of pharmaceuticals in sewage water and sludge during wastewater treatment. Water Research 45: $1165-1176$.

Kwon, J.-W. \& K. L. Armbrust, 2008. Aqueous solubility, n-octanol-water partition coefficient, and sorption of five selective serotonin reuptake inhibitors to sediments and soils. Bulletin of Environmental Contamination and Toxicology 81: 128-135.

López-Serna, R. \& M. Petrović, 2012. Occurrence and distribution of multi-class pharmaceuticals and their active metabolites and transformation products in the Ebro River basin (NE Spain). Science of the Total Environment 440: 280-289.

Madureira, T. V., J. C. Barreiro, M. J. Rocha, E. Rocha, Q. B. Cass \& M. E. Tiritan, 2010. Spatiotemporal distribution of pharmaceuticals in the Douro River estuary (Portugal). Science of the Total Environment 408: 5513-5520.

Mucha, A. P., C. M. R. Almeida, C. M. Magalhães, M. T. S. D. Vasconcelos \& A. A. Bordalo, 2011. Salt marsh plantmicroorganism interaction in the presence of mixed contamination. International Biodeterioration and Biodegradation 65: 326-333.

Oyetibo, G. O., K. Miyauchi, Y. Huang, M.-F. Chien, M. O. Ilori, O. O. Amund \& G. Endo, 2017. Biotechnological remedies for the estuarine environment polluted with heavy metals and persistent organic pollutants. International Biodeterioration \& Biodegradation 119: 614-625.

Paíga, P., L. H. M. L. M. Santos, S. Ramos, S. Jorge, J. G. Silva \& C. Delerue-Matos, 2016. Presence of pharmaceuticals in the Lis river (Portugal): sources, fate and seasonal variation. Science of the Total Environment 573: 164-177.

Pereira, A. M. P. T., L. J. G. Silva, L. M. Meisel, C. M. Lino \& A. Pena, 2014. Environmental impact of pharmaceuticals from Portuguese wastewaters: geographical and seasonal occurrence, removal and risk assessment. Environmental Research 136: 108-119.

Reis-Santos, P., M. Pais, B. Duarte, I. Caçador, A. Freitas, A. S. Vila Pouca, J. Barbosa, S. Leston, J. Rosa, F. Ramos, H. N. Cabral, B. M. Gillanders \& V. F. Fonseca, 2018. Screening of human and veterinary pharmaceuticals in estuarine waters: a baseline assessment for the Tejo estuary. Marine Pollution Bulletin 135: 1079-1084.

Ribeiro, H., A. P. Mucha, C. Marisa, R. Almeida \& A. A. Bordalo, 2013. Bacterial community response to petroleum contamination and nutrient addition in sediments from a temperate salt marsh. Science of the Total Environment 458-460: 568-576.

Rocha, A. C. S., C. M. R. Almeida, M. C. P. Basto \& M. T. S. D. Vasconcelos, 2015. Influence of season and salinity on the exudation of aliphatic low molecular weight organic acids (ALMWOAs) by Phragmites australis and Halimione portulacoides roots. Journal of Sea Research 95: 180-187.

Sauvêtre, A. \& P. Schröder, 2015. Uptake of carbamazepine by rhizomes and endophytic bacteria of Phragmites australis. Frontiers in Plant Science 6: 83.

Sayen, S., C. Rocha, C. Silva, E. Vulliet, E. Guillon \& C. M. R. Almeida, 2019. Enrofloxacin and copper plant uptake by Phragmites australis from a liquid digestate: single versus combined application. Science of the Total Environment 664: 188-202.

Schröder, P., D. Daubner, H. Maier, J. Neustifter \& R. Debus, 2008. Phytoremediation of organic xenobiotics - glutathione dependent detoxification in Phragmites plants from European treatment sites. Bioresource Technology 99: 7183-7191. 
Silva, L. J. G., A. M. P. T. Pereira, L. M. Meisel, C. M. Lino \& A. Pena, 2014. A one-year follow-up analysis of antidepressants in Portuguese wastewaters: occurrence and fate, seasonal influence, and risk assessment. Science of the Total Environment 490: 279-287.

Sophia, A. \& E. C. Lima, 2018. Removal of emerging contaminants from the environment by adsorption. Ecotoxicology and Environmental Safety 150: 1-17.

Sousa, A. F. P. de, 2014. Otimização de um método de análise de poluentes emergentes (fármacos) em águas. Report for Chemistry Degree. Faculty of Sciences, University of Porto, Portugal.

Sousa, J. C. G., A. R. Ribeiro, M. O. Barbosa, C. Ribeiro, M. E. Tiritan, M. F. R. Pereira \& A. M. T. Silva, 2019. Monitoring of the $17 \mathrm{EU}$ Watch List contaminants of emerging concern in the Ave and the Sousa Rivers. Science of the Total Environment 649: 1083-1095.

Sun, J., M.-H. Wang \& Y.-S. Ho, 2012. A historical review and bibliometric analysis of research on estuary pollution. Marine Pollution Bulletin 64: 13-21.

Taheran, M., M. Naghdi, S. K. Brar, M. Verma \& R. Y. Surampalli, 2018. Emerging contaminants: here today, there tomorrow! Environmental Nanotechnology, Monitoring \& Management 10: 122-126.

Talaya, A. F. C., 2015. Desarrollo de métodos de análisis de contaminantes emergentes (fármacos) en sedimentos para un estudio futuro de la influencia de las plantas de sapal en su distribución en ambientes estuarinos. Report for Chemistry Degree. ERAMUS Programme. Valencia University, Spain.

Tang, Y., X.-M. Li, Z.-C. Xu, Q.-W. Guo, C.-Y. Hong \& Y.-X. Bing, 2014. Removal of naproxen and bezafibrate by activated sludge under aerobic conditions: kinetics and effect of substrates. Biotechnology and Applied Biochemistry 61: 333-341.

Thiele-Bruhn, S. \& M.-O. Aust, 2004. Effects of pig slurry on the sorption of sulfonamide antibiotics in soil. Archives of Environmental Contamination and Toxicology 47: 31-39.

Thomas, K. V. \& M. J. Hilton, 2004. The occurrence of selected human pharmaceutical compounds in UK estuaries. Marine Pollution Bulletin 49: 436-444.

Trovó, A. G., S. A. S. Melo \& R. F. P. Nogueira, 2008. Photodegradation of the pharmaceuticals amoxicillin, bezafibrate and paracetamol by the photo-Fenton process application to sewage treatment plant effluent. Journal of Photochemistry and Photobiology A: Chemistry 198: 215-220.

US EPA, 1991. Evaluation of dredged material proposed for ocean disposal. Evaluation 228: 220-228.

Yan, C., Y. Yang, J. Zhou, M. Nie, M. Liu \& M. F. Hochella, 2015. Selected emerging organic contaminants in the Yangtze Estuary, China: a comprehensive treatment of their association with aquatic colloids. Journal of Hazardous Materials 283: 14-23.

Yang, Y., J. Fu, H. Peng, L. Hou, M. Liu \& J. L. Zhou, 2011. Occurrence and phase distribution of selected pharmaceuticals in the Yangtze Estuary and its coastal zone. Journal of Hazardous Materials 190: 588-596.

Yu, J. T., E. J. Bouwer \& M. Coelhan, 2006. Occurrence and biodegradability studies of selected pharmaceuticals and personal care products in sewage effluent. Agricultural Water Management 86: 72-80.

Publisher's Note Springer Nature remains neutral with regard to jurisdictional claims in published maps and institutional affiliations. 